\title{
KAJIAN KAPASITAS SALURAN DAERAH IRIGASI BAING DI KABUPATEN SUMBA TIMUR PROVINSI NUSA TENGGARA TIMUR
}

\author{
Oleh: Muchamad Arif Budiyanto', Tornado M. Ratu Ropa ${ }^{2}$ \\ E-mail: arifbudiyanto.sipil@gmail.com
}

\begin{abstract}
ABSTRAK: Irigasi merupakan kegiatan-kegiatan yang berhubungan dengan usaha mendapatkan air, antara lain untuk mengairi sawah, ladang, perkebunan, yang sebagai intinya adalah untuk keperluan pertanian dalam usaha tani. Daerah Irigasi Baing yang secara administratif berada di Desa Laipandak, Kecamatan Wulla Waijelu, Kabupaten Sumba Timur, Provinsi Nusa Tenggara Timur. Sumber air Daerah Irigasi ini berasal dari Sungai Baing dengan areal Potensial seluas $2.000,00 \mathrm{Ha}$ dengan 1.630,00Ha dan 302,00Ha untuk Saluran Sekunder Baing. Tujuan dari penelitian ini untuk meninjau kapasitas saluran jaringan irigasi agar kebutuhan air pada Daerah Irigasi Baing dapat terpenuhi.

Teknik pengambilan data yang digunakan adalah data Sekunder yang diperoleh dari Balai Wilayah Sungai Nusa Tenggara II yaitu data topografi (2014), data Curah Hujan dan data Klimatologi 10 tahun terakhir dari Tahun 2009-2018 serta data Primer diperoleh dari hasil penelitian/survey langsung di lapangan. Metode pengolahan data dilakukan dengan metode Penman Modifikasi untuk menghitung Evapotranspirasi, kebutuhan air irigasi (NFR) dan rumus Strickler untuk debit saluran.

Setelah dilakukan perhitungan maka didapat nilai Evapotranspirasi Potensial Metode Penman Modifikasi sebesar 3,115 mm/hari, kebutuhan air irigasi (NFR) sebesar 1,34 Itr/dtk/ha, maka untuk saluran sekuder (SSR.1) ruas B.BG.1-BG.2 dengan luas areal 1.630,00 Ha diperoleh nilai $Q=3,4$ $\mathrm{m}^{3} / \mathrm{dtk}, A=5,60 \mathrm{~m}^{2}, V=0,60 \mathrm{~m} / \mathrm{dtk}, I=0,0018559$, dan lebar dasar saluran $(\mathrm{b})=3,20 \mathrm{~m}$, tinggi muka air $(h)=1,75 \mathrm{~m}$, tinggi jagaan $(w)=0,25 \mathrm{~m}$. Sedangkan untuk saluran sekuder (SSR.2) ruas B.BG.1-BLM.1 dengan luas areal 302,00 Ha diperoleh nilai $Q=0,62 \mathrm{~m}^{3} / \mathrm{dtk}, A=1,24 \mathrm{~m}^{2}, V=0,50$ $\mathrm{m} / \mathrm{dtk}, I=0,0267291$, dan lebar dasar saluran $(b)=1,65 \mathrm{~m}$, tinggi muka air $(\mathrm{h})=0,75 \mathrm{~m}$, tinggi jagaan $(w)=0,25 \mathrm{~m}$.
\end{abstract}

Kata Kunci : Irigasi, Debit, Dimensi, Saluran.

\section{PENDAHULUAN}

\subsection{Latar Belakang}

Salah satu target pemerintah saat ini adalah menjadikan Indonesia sebagai Negara swasembada pangan. Sehingga dicanangkan berbagai program pemerintah untuk mencapai tujuan tersebut, bahkan daerah-daerah terpencil dan tertinggal diupayakan untuk berkembang seperti Provinsi Nusa Tenggara Timur (NTT) yang diketahui bahwa pertanian merupakan mata pencaharian pokok msyarakat.

Irigasi merupakan kegiatan-kegiatan yang berhubungan dengan usaha mendapatkan air untuk mengairi sawah, ladang, perkebunan, yang sebagai intinya adalah untuk keperluan pertanian dalam usaha tani. Salah satu Kabupaten di Provinsi NTT yang selalu mengalami masalah kekeringan adalah Kabupaten Sumba Timur yang merupakan daerah yang memiliki jumlah penduduk dengan mata pencaharian bertani lebih banyak dibanding mata pencaharian lainnya (Badan Nasional Penanggulangan Bencana, 2018).

1) adalah staf pengajar Program Studi Teknik Sipil Universitas Cokroaminoto Yogyakarta

2) adalah Mahasiswa Program Studi Teknik Sipil Universitas Cokroaminoto Yogyakarta

32 Kajian Kapsitas Saluran Daerah Irigasi Baing di Kabupaten Sumba Timur Provinsi Nusa Tenggara Timur (Muchamad Aruf Budiyanto, Tornado M. Ratu Ropa) 
Dalam rangka meningkatkan kesejahteraan petani, diperlukan penyediaan sarana dan prasarana irigasi untuk mengairi lahan pertanian.Dalam hal ini khususnya Daerah Irigasi Baing yang secara administratif berada di Desa Watu Laipandak, Kecamatan Wula Waijelu, Kabupaten Sumba Timur, Provinsi NTT. Sumber air Daerah Irigasi ini berasal dari sungai Baing (Dinas Pekerjaan Umum Kabupaten Sumba Timur, tahun 2014), dan memiliki areal potensial seluas 2.000,00 Ha. Potensi yang dimiliki oleh Daerah Irigasi Baing adalah daerah persawahan dan tanaman-tanaman lain seperti jambu mente, jagung, sayur-sayuran, dan umbi-umbian.

\subsection{Tujuan Penelitian}

Adapun tujuan dari penelitian ini adalah:

1. Menghitung besar kebutuhan air irigasi per hektar pada Daerah Irigasi Baing di Kabupaten Sumba Timur; dan

2. Menghitung dimensi saluran dan peningkatan irigasi pada Daerah Irigasi Baing di Kabupaten Sumba Timur pada ruas Saluran Sekunder Waijelu pada Daerah Irigasi Baing di Kabupaten Sumba Timur.

\section{TINJAUAN PUSTAKA DAN LANDASAN TEORI}

\subsection{Tinjauan Pustaka}

\subsubsection{Pengertian Irigasi}

Kata irigasi diambil dari bahas asing: "irrigaite" dalam bahasa Belanda atau "irrigation" dalam bahasa Inggris. Dalam Peraturan Pemerintah (PP) No. 23 Tahun 1982 Pasal 1, pengertian irigasi, bangunan irigasi, dan petak irigasi adalah sebagai berikut:

1. Irigasi adalah usaha penyediaan dan pengaturan air untuk menunjang pertanian.

2. Jaringan irigasi adalah saluran dan bangunan yang merupakan satu kesatuan dan diperlukan untuk pengaturan air irigasi mulai dari penyediaan, pengambilan, pembagian pemberian dan penggunaannya.

3. Daerah irigasi adalah kesatuan wilayah yang mendapat air dari satu jaringan irigasi.

4. Petak irigasi adalah petak tanah yang memperoleh air irigasi.

\subsubsection{Tujuan Dan Manfaat Irigasi}

1. Tujuan Irigasi pada suatu daerah adalah upaya rekayasa teknis untuk penyediaaan dan pengaturan air dalam menunjang proses produksi pertanian, secara teknis dan sistematis.

2. Manfaat Irigasi antara lain untuk membasahi tanah, untuk mengatur pembasahan tanah, untuk menyuburkan tanah, untuk kolmatase, dan untuk pengelontoran air.

\subsubsection{Kinerja Sistem Irigasi}

Menurut Olvi Pamadya Utaya Kusuma, dkk. (2012) dan Supriyono, dkk. (2013) menganalisis kinerja jaringan irigasi untuk menentukan skala prioritas penanganan sesuai Peraturan Menteri Pekerjaan Umum Nomor 32/PRT/M/2007 tanggal 11 September 2007 tentang Pedoman Operasi dan Pemeliharaan Jaringan Irigasi. Evaluasi kinerja sistem irigasi adalah untuk mengetahui kondisi sistem irigasi yang meliputi:

1. Kondisi keberfungsian prasarana bangunan irigasi yang meliputi kondisi; bangunan utama, saluran pembawa, bangunanpada saluran pembawa, saluran pembuang, jalan inspeksi, dan kantor dan gudang.

2. Besarnya produktifitas tanam yang meliputi ; pemenuhan kebutuhan air irigasi (faktor K), realisasi luas tanam, dan produktifitas padi. 
3. Ketersediaan dan kemanfaatan sarana penunjang yang meliputi; peralatan operasi dan pemeliharaan, transportasi, alat-alat kantor Perwakilan Balai, dan alat komunikasi.

4. Kondisi organisasi personalia yang meliputi; organisasi operasi dan pemeliharaan dan personalia.

5. Kondisi dokumentasi jaringan irigasi yang meliputi; buku data daerah irigasi, peta dan gambar-gambar skema jaringan irigasi serta gambar pelaksanaan operasi dan pemeliharaan.

6. Kondisi P3A.

\subsubsection{Pemberian Air Irigasi}

Ketersediaan air yang semakin terbatas, sistem pemberian air irigasi yang lebih efisien dalam penggunaan air irigasi dapat mengatasi masalah kekurangan air pada petak tersier sawah. Menilai efisiensi irigasi pada petak tersier sawah menggunakan teknik drum padi dan teknik inflow-outflow, sebagai neraca kesetimbangan debit air di petak tersier sawah dengan mengamati parameter-paramater yang sangat mempengaruhi efisiensi pemberian air irigasi, yaitu: evapotranspirasi, perkolasi, curah hujan efektif, dan debit air irigasi (Akmal, dkk., 2014).

\subsubsection{Klasifikasi Jaringan Irigasi}

Klasifikasi jaringan irigasi bila ditinjau dari cara pengaturan, cara pengukuran aliran air dan fasilitasnya, dibedakan atas 3 tingkatan yaitu:

1. Jaringan irigasi sederhana;

2. Jaringan irigasi semi teknis; dan

3. Jaringan irigasi teknis.

\subsubsection{Jenis - Jenis Saluran Dalam Jaringan Irigasi}

Dalam suatu daerah irigasi teknis, klasifikasi saluran tersebut adalah sebagai berikut:
1. Saluran Primer
2. Saluran Sekunder
3. Saluran Tersier
4. Saluran Kuarter
5. Saluran Sub Kuarter (Saluran cacing)

\subsection{LandasanTeori}

\subsubsection{Bangunan Irigasi}

1. Bangunan distribusi

a. Bangunan Bagi

Bangunan yang terletak pada saluran primer yang mebagi air ke saluran sekunder atau pada saluran sekunder yang membagi air ke saluran saluran sekunder lainnya.

b. Bangunan Sadap

Bangunan yang terletak di saluran primer ataupun sekunder yang memberi air kepada saluran tersier. Bangunan sadap dibagi menjadi dua yaitu bangunan sadap sekunder dan bangunan sadap tersier.

2. Bangunan Silang terdiri dari bangunan Talang, bangunan Siphon, dan Goronggorong di jaringan irigasi.

3. Bangunan Pengurangan Kemiringan terdiri dari Bangunan terjun dan Got miring. 


\subsubsection{Analisa Hidrologi}

Untuk analisa hidrologi, dapat dilakukan dengan 3 cara yaitu:

1. Perhitungan Distribusi Curah Hujan Rata-Rata;

2. Analisa Evapotranspirasi; dan

3. Prosedur Perhitungan Eto.

\subsubsection{Analisa Kebutuhan Air Untuk Irigasi}

Perkiraan kebutuhan air irigasi dapat dihitung dengan menggunakan persamaan yaitu:

1) Kebutuhan air bersih di sawah untuk padi (NFR)

$$
\text { NFR }=E t c+P+W L R-R e
$$

2) Kebutuhan air irigasi untuk padi di intake (WDR)

$$
\text { WDR } \quad=\frac{N F R}{e}
$$

3) Kebutuhan air irigasi untuk Palawija

IR $=\frac{\text { Etc }-\mathrm{Re}}{\mathrm{e}}$

Keterangan :

Etc $=$ Penggunaan konsumtif $(\mathrm{mm} / \mathrm{hari})$

$\mathrm{P} \quad=$ Perkolasi

WRL = Penggantian lapisan air

$\mathrm{Re} \quad=$ Curah hujan efektif

$\mathrm{E} \quad=$ Total efisiensi irigasi

4) Persamaan untuk menghitung kebutuhan bersih air irigasi di sawah adalah :

$$
\mathrm{DR}=\left(\frac{\mathrm{IR}+\mathrm{Etc}+\mathrm{Rw}+\mathrm{p}-\mathrm{ER}}{\mathrm{IE}}\right) .
$$

Keterangan :

$\mathrm{DR}=$ Kebutuhan air irigasi $(\mathrm{l} / \mathrm{dt} / \mathrm{ha})$

IR = Kebutuhan air untuk penyiapan lahan $(\mathrm{mm} / \mathrm{hari})$

Etc $=$ Kebutuhan air konsumtif (mm/hari)

$\mathrm{Rw}=$ Kebutuhan air untuk penggantian lapisan ( $\mathrm{mm} / \mathrm{hari}$ )

$P \quad=$ Perkolasi ( $\mathrm{mm} /$ hari)

$\mathrm{ER}=$ Hujan efektif $(\mathrm{mm} /$ hari $)$

$\mathrm{IE}=$ Efisiensi irigasi $(\mathrm{mm} / \mathrm{hari})$

$\mathrm{A}=$ Luas areal irigasi $(\mathrm{Ha})$

\subsubsection{Tata Pola Tanam}

1. Pengertian pola tanam adalah suatu urutan tanam pada sebidang lahan dalam 1 tahun, termasuk masa pengolahan tanah.

2. Maksud dan tujuan penerapan pola tanam yakni untuk memanfaatkan sumber daya air secara optimal dan mengurangi resiko kegagalan panen.

3. Faktor-faktor yang mempengaruhi pola tanam antara lain iklim, topografi, debit air yang tersedia, jenis tanah dan sosial ekonomi. 


\subsubsection{Perencanaan Jaringan Irigasi}

\section{Menghitung Debit Rencana Saluran}

Besarnya debit rencana pada saluran irigasi dihitung dengan menggunakan rumus berikut, (KP - 03, 2013):

Q

$$
=\frac{C \cdot N F R \cdot A}{e} \text {. }
$$

Qrenc $=\frac{Q s}{e} \ldots$

Qpetak $=\frac{\text { Qrenc }}{1000}\left(\mathrm{~m}^{3} / \mathrm{dtk}\right)$

Keterangan :
Qrenc = Debit rencana (Itr/dtk)
QS $\quad=$ Debit saluran (Itr/dtk)
C = Koefisien pengurangan karena adanya sistem golongan $(c=1)$

NFR = Kebutuhan air bersih disawah (Itr/dtk/ha)

$E \quad=$ Efisiensiirigasi $(0,65)$

$A \quad=$ Luas areal (ha)

Rumus-rumus aliran dan saluran :

$Q=V \cdot A$

$V=K \cdot R^{2 / 3} \cdot I^{1 / 2} \cdot$

$R=\frac{A}{P}$

$A=b . h$ (untuk saluran berpenampang persegi panjang).

$P=b+2 h$ (untuk saluran berpenampang persegi panjang)

Keterangan :

$Q \quad=$ Debit aliran (Itr/dtk)

$V=$ Kecepatan aliran $(\mathrm{m})$

$K=$ Koefisien kekasaran Strickler $\left(m^{1 / 3} / \mathrm{dt}\right)$

$R=$ Jari-jari hidrolis $(\mathrm{m})$

$A=$ Luas penampang $\left(\mathrm{m}^{2}\right)$

$P=$ Keliling basah $(\mathrm{m})$

$I=$ Kemiringan saluran

$b=$ Lebar saluran $(\mathrm{m})$

$h \quad=$ Tinggi air $(\mathrm{m})$ 
2. Koefisien Kekasaran Strickler

Tabel 1 Koefisien Kekasaran Strickler

\begin{tabular}{|c|l|c|}
\hline No & \multicolumn{1}{|c|}{ Jenis Saluran } & Harga $(\mathrm{K})$ \\
\hline 1 & Saluran tanah & \\
& a. $\mathrm{Q}<1 \mathrm{~m}^{3} / \mathrm{dtk}$ & 35 \\
& b. $1<\mathrm{Q}<10$ & 40 \\
& C. $5<\mathrm{Q}<10$ & 42,5 \\
& d. $\mathrm{Q}>10$ & 45 \\
\hline 2 & Satu sisi talud pasangan & 42 \\
\hline 3 & Talud pasangan dasar tanah & 45 \\
\hline 4 & Kedua dasar saluran saluran pasangan & 60 \\
\hline 5 & Satu sisi talud dari beton & 45 \\
\hline 6 & Kedua talud dari beton dasar dari tanah & 50 \\
\hline 7 & Kedua talud dari beton dasar saluran dari tanah & 70 \\
\hline 8 & Saluran dari pasangan dan diplester & 75 \\
\hline
\end{tabular}

Sumber : Kriteria Perencanaan Irigasi (KP-03) Saluran, Direktorat Jenderal Pengairan tahun 2013

3. Tinggi Jagaan (w)

Tabel 2 Tinggi Jagaan Maksimum Yang Dilakukan Untuk Saluran Irigasi

\begin{tabular}{|c|c|c|c|}
\hline \multirow{2}{*}{ No } & \multirow{2}{*}{ Debit $\left(\mathrm{m}^{3} / \mathrm{dtk}\right)$} & Tanah $(\mathrm{m})$ & Tinggi Jagaan \\
\cline { 3 - 4 } & $<0,5$ & 0,40 & 0,20 \\
\hline 1 & $0,5-1,5$ & 0,50 & 0,20 \\
\hline 2 & $1,5-5,0$ & 0,60 & 0,25 \\
\hline 3 & $5-10$ & 0,75 & 0,30 \\
\hline 4 & $10-15$ & 0,85 & 0,40 \\
\hline 5 & $>15,0$ & 1,00 & 0,50 \\
\hline 6 & & &
\end{tabular}

Sumber : Kriteria Perencanaan Irigasi (KP-03) Saluran, Direktorat Jenderal Pengairan tahun 2013.

\section{Kemiringan Sisi Saluran (m)}

Tabel 3 Kemiringan minimum talut untuk berbagai bahan tanah

\begin{tabular}{|c|l|c|c|}
\hline No & \multicolumn{1}{|c|}{ Bahan Tanah } & Simbol & Kisaran Kemiringan (m) \\
\hline 1 & Batu & & 0,25 \\
\hline 2 & Gambut kenyal & $\mathrm{Pt}$ & $1-2$ \\
\hline 3 & Lempung kenyal, geluh, tanah lus & $\mathrm{CL}, \mathrm{CH}, \mathrm{Mh}$ & $1-2$ \\
\hline 4 & Lempung pasiran, tanah pasiran, kohesif & $\mathrm{SC}, \mathrm{SM}$ & $1,5-2,5$ \\
\hline No & \multicolumn{1}{|c|}{ Bahan Tanah } & Simbol & Kisaran Kemiringan (m) \\
\hline 5 & Pairan lanauan & $\mathrm{SM}$ & $2-3$ \\
\hline 6 & Gambut lunak & $\mathrm{Pt}$ & $3-4$ \\
\hline
\end{tabular}

Sumber: Kriteria Perencanaan Irigasi (KP-03) Saluran, Direktorat Jenderal Pengairan tahun 2013.

\section{Perbandingan Lebar Dasar Saluran}

Saluran kecil didesain dengan perbandingan sebagai berikut:

a) Luas penampang saluran (A) Untuk saluran berpenampang persegi panjang

$A=b . h$. . .

b) Keliling basah $(P)$

Kajian Kapsitas Saluran Daerah Irigasi Baing di Kabupaten Sumba Timur Provinsi

Nusa Tenggara Timur (Muchamad Aruf Budiyanto, Tornado M. Ratu Ropa) 
Untuk saluran berpenampang persegi panjang

$P \quad=b+2 h$

c) Jari-jari hidrolis $(\mathrm{R})$

$R=A / P$

d) Perbandingan antara lebar dasar saluran dengan kedalaman air

$b / h \quad=1 \rightarrow b=h$

e) Kecepatan aliran (V)

$V=Q / A$

f) Kontrol Froude

$$
\text { Fru }=\frac{V}{\sqrt{g x h}} \text {. }
$$

\section{METODOLOGI PENELITIAN}

\subsection{Lokasi Penelitian}

Lokasi yang digunakan sebagai daerah penelitian adalah Daerah Irigasi Baing, Desa Laipandak, Kecamatan Wula Waijelu, Kabupaten Sumba Timur, Propinsi NTT. Daerah Irigasi Baing dapat ditempuh dengan kendaraan roda 4 maupun roda 2 melalui jalan raya dari Waingapu ke arah Timur Pulau Sumba dngan jarak tempuh $\pm 120 \mathrm{~km}$, kemudian belok kiri menuju lokasi melalui jalan setapak (jala kampung) kearah pinggir sungai (lokasi Bendung) sejauh $\pm 200 \mathrm{~m}$.

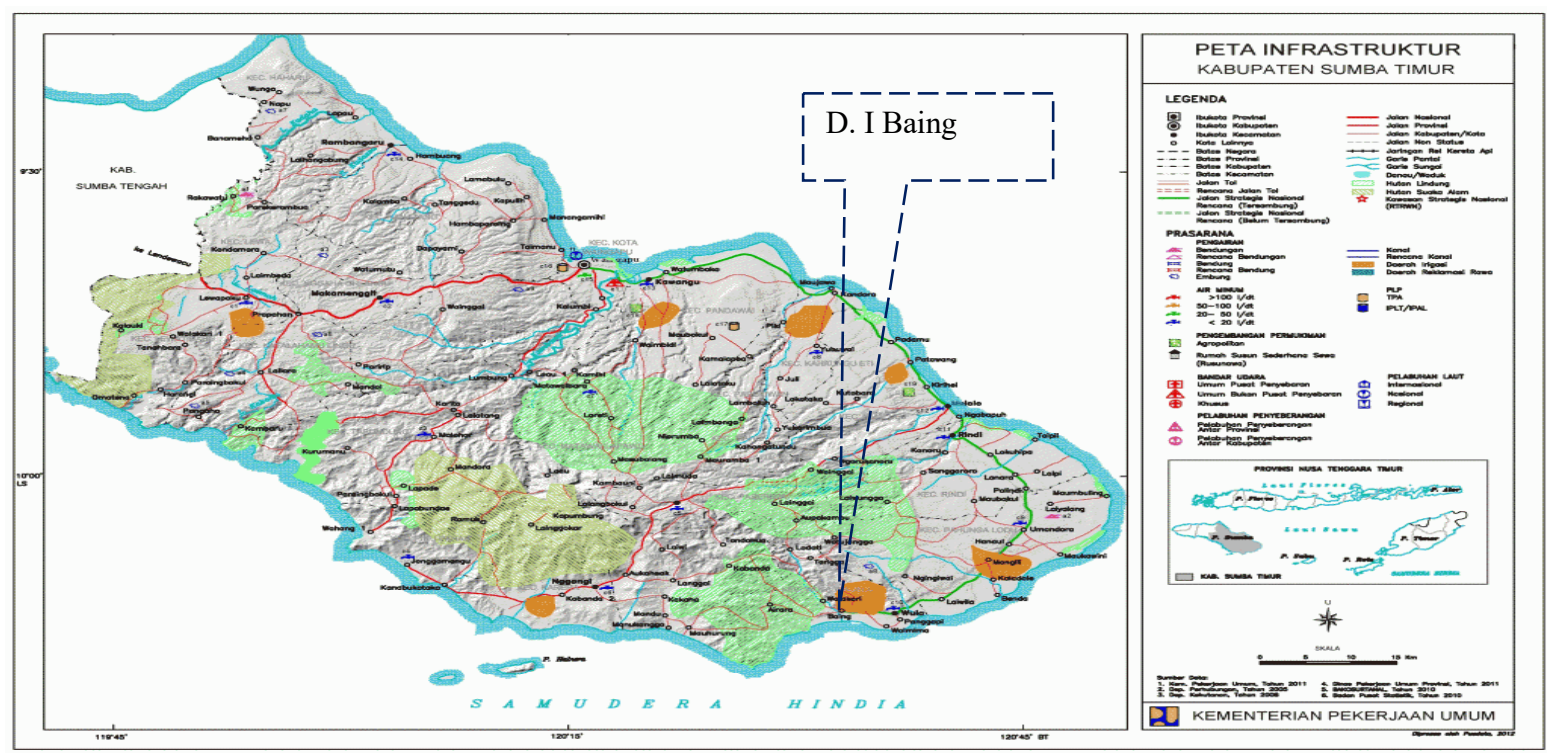

Sumber : Departemen Kementerian PU, (2012)

Gambar 1 Peta Situasi Lokasi Penelitian

38 Kajian Kapsitas Saluran Daerah Irigasi Baing di Kabupaten Sumba Timur Provinsi Nusa Tenggara Timur (Muchamad Aruf Budiyanto, Tornado M. Ratu Ropa) 


\subsection{Data}

\subsubsection{Sumber Data}

1. Data primer

Data primer yang gunakan yakni terdiri dari pengukuran situasi saluran irigasi, pengukuran debit sesaat, wawancara (interview), dan pengukuran panjang saluran yang ada.

2. Data sekunder

Data sekunder yang gunakan adalah data curah hujan dan data klimatologi 10 tahun terakhir dari tahun 2009 sampai dengan tahun 2018, serta data topografi.

\subsubsection{Metode Pengumpulan Data}

1. Metode Studi Kepustakaan adalah untuk mendapatkan data sekunder.

2. Metode Wawancara (Interview) untuk memperoleh informasi dengan mencakup masalah yang dibahas oleh penulis.

\subsubsection{Analisa Data}

3. Metode Studi Lapanga adalah untuk mendapatkan data primer.
1. Analisa Data, terdiri dari Analisa Hidrologi dan Analisa Klimatologi.
2. Analisa Perhitungan Curah Hujan Rata-Rata Daerah.
3. Analisa Perhitungan Curah Hujan Efektif (Re).
4. Analisa Perhitungan Kebutuhan Air (NFR).
5. Analisa Perhitungan Debit Saluran.
6. Rencana Jaringan Irigas 


\subsubsection{Bagan Alir Penulisan}

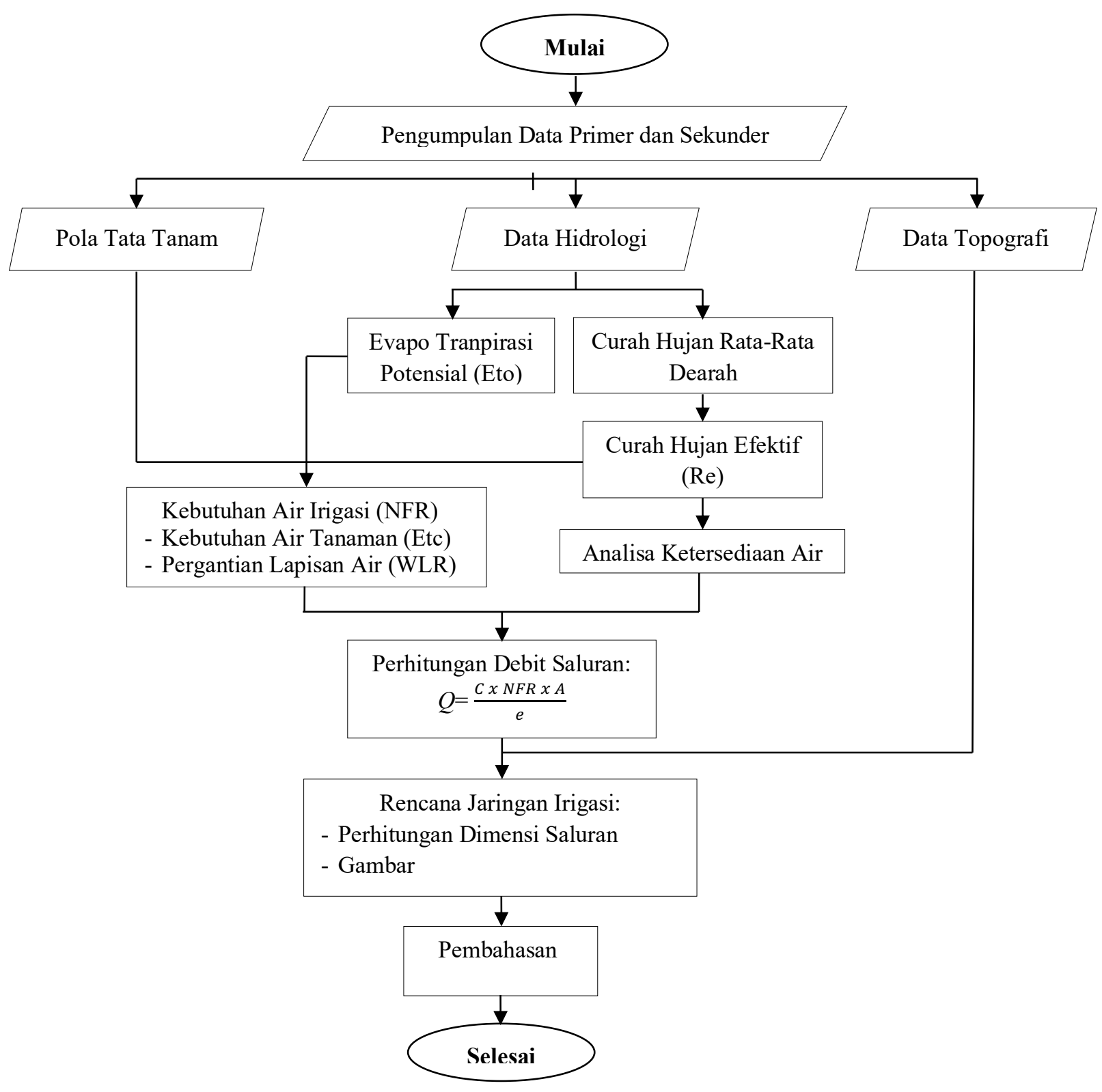

Gambar 2 Bagan Alir Penelitian 


\section{PEMBAHASAN}

\subsection{Perhitungan Evapotranspirasi}

Perhitungaan evapotranspirasi potensial metode Penman modifikasi bulan November I

Diketahui :

$$
\begin{array}{ll}
(c) & =0,927 \\
(W) & =0,771 \\
(R n) & =2,883 \mathrm{~mm} / \mathrm{hr} \\
(1-W) & \quad=0,229 \\
f(u) & =0,500 \mathrm{~m} / \mathrm{dtk} \\
(\text { ea }- \text { ed }) & =9,940 \mathrm{mmbar}
\end{array}
$$

Evapotranspirasi potensial (Eto) bulan November

$$
\begin{aligned}
\text { Eto } & =c \\
& =0,927 \cdot[0,771.2,883+(0,229) 0,500(9,940)] \\
& =3,115 \mathrm{~mm} / \text { hari }
\end{aligned}
$$

\subsection{Perhitungan Kebutuhan Air Irigasi}

Perhitungan kebutuhan air penyiapan lahan bulan Nopember I :

Diketahui :

$$
\begin{array}{rll}
e^{\wedge} k & = & \text { Bilangan eksponen } 2,257 \\
M & = & 5,426 \mathrm{~mm} / \text { hari } \\
k & = & 0,814 \\
I R & =\frac{M e^{k}}{e^{k}-1} \\
& =\frac{5,426 \times 2,257^{0,814}}{\left(2,257^{0,814}\right)-1} \\
& =\frac{7,685}{0,940} \\
& =8,177 \mathrm{~mm} / \mathrm{hari} .
\end{array}
$$

\subsection{Penggunaan Konsumtif (Evapotranspirasi)}

Perhitungan Kebutuhan Air Konsumtif Untuk Tanaman (Penggunaan Konsumtif) terlihat pada tabel berikut dengan masa tanam tidak serentak berperiode tengah bulanan dengan waktu bebas 1,5 (satu setengah) bulan diandaikan mencakup tiga bulan yang disediakan untuk penyiapan lahan, (45 hari). 


\subsection{Kebutuhan Air Untuk Penggantian Lapisan Air (WLR)}

Kebutuhan air untuk penggantian lapisan air dilakukan sebanyak dua kali dalam sebulan. Tabel pergantian lapisan air dapat dilihat pada tabel dibawah ini:

Tabel 4 Kebutuhan Air Untuk Pergantian Lapisan Air (WLR)

\begin{tabular}{|c|c|c|c|c|c|}
\hline Bulan & Minggu & WLR1 & WLR2 & WLR3 & WLR (rata-rata) \\
\hline \multirow{2}{*}{ Nopember } & 1 & & & & \\
\hline & 2 & & & & \\
\hline \multirow{2}{*}{ Desember } & 1 & & & & \\
\hline & 2 & 3.30 & & & 1.10 \\
\hline \multirow{2}{*}{ Januari } & 1 & & 3.30 & & 1.10 \\
\hline & 2 & 3.30 & & 3.30 & 2.20 \\
\hline \multirow{2}{*}{ Pebruari } & 1 & & 3.30 & & 1.10 \\
\hline & 2 & & & 3.30 & 1.10 \\
\hline \multirow{2}{*}{ Maret } & 1 & & & & \\
\hline & 2 & & & & \\
\hline \multirow{2}{*}{ April } & 1 & & & & \\
\hline & 2 & & & & \\
\hline \multirow{2}{*}{ Mei } & 1 & 3.30 & & & 1.10 \\
\hline & 2 & & 3.30 & & 1.10 \\
\hline \multirow{2}{*}{ Juni } & 1 & 3.30 & & 3.30 & 2.20 \\
\hline & 2 & & 3.30 & & 1.10 \\
\hline \multirow{2}{*}{ Juli } & 1 & & & 3.30 & 1.10 \\
\hline & 2 & & & & \\
\hline \multirow{2}{*}{ Agustus } & 1 & & & & \\
\hline & 2 & & & & \\
\hline \multirow{2}{*}{ September } & 1 & & & & \\
\hline & 2 & & & & \\
\hline \multirow{2}{*}{ Oktober } & 1 & & & & \\
\hline & 2 & & & & \\
\hline
\end{tabular}

Sumber : Hasil Perhitungan 2019 


\subsection{Curah Hujan Andalan (R80)}

Perhitungan Curah Hujan Andalan (R80) dapat dilihat pada tabel berikut :

Tabel 5 Perhitungan Curah Hujan Andalan (R80)

\begin{tabular}{|c|c|c|c|c|c|c|c|c|c|c|c|c|c|c|c|c|c|c|c|c|c|c|c|c|c|c|}
\hline 72,73 & 28 & 97 & & 94 & 83 & 95 & 79 & 66 & 13 & 0 & 0 & 0 & 0 & 0 & 0 & 0 & 0 & 0 & 0 & 0 & & & 5 & & 78 & 52 \\
\hline $\mathrm{R} 80$ & 8,02 & 41 & & 70,8 & 45,4 & 60,3 & 54,1 & 43,0 & 10,6 & 0 & 0 & 0 & 0 & 0 & 0 & 0 & 0 & 0 & 0 & 0 & & & 54 & 40 & 41,1 & 10,4 \\
\hline 81,82 & 3 & 28 & & 65 & 36 & 52 & 48 & 37 & 10 & 0 & 0 & 0 & 0 & 0 & 0 & 0 & 0 & 0 & 0 & 0 & & & 2 & & 32 & 0 \\
\hline \multirow{4}{*}{\multicolumn{3}{|c|}{ Curah Hujan Efektif (Re 80) }} & \multicolumn{24}{|c|}{ Curah Hujan mm/1/2 Bulanan } \\
\hline & & & \multicolumn{2}{|c|}{ JAN } & \multicolumn{2}{|c|}{ FEB } & \multicolumn{2}{|c|}{ MAR } & \multicolumn{2}{|c|}{ APR } & \multicolumn{2}{|c|}{ MEI } & & & \multicolumn{2}{|c|}{ JUL } & \multicolumn{2}{|c|}{ AGUST } & \multicolumn{2}{|c|}{ SEPT } & \multicolumn{2}{|c|}{ 0KT } & \multicolumn{2}{|c|}{$\mathrm{NOV}$} & \multicolumn{2}{|c|}{ DES } \\
\hline & & & 1 & 2 & 1 & 2 & 1 & 2 & 1 & 2 & 1 & 2 & 1 & 2 & 1 & 2 & 1 & 2 & 1 & 2 & 1 & 2 & 1 & 2 & 1 & 2 \\
\hline & & & 8.02 & 41.7 & 70.8 & 45.4 & 60.34 & 54.14 & 43.04 & 10.6 & 0 & 0 & 0 & 0 & 0 & 0 & 0 & 0 & 0 & 0 & 0 & 0 & 4.54 & 5.40 & 41.10 & 10.4 \\
\hline \multicolumn{3}{|c|}{$(\mathrm{mm} / 1 / 2)$ bulan } & 0.534667 & 2.60625 & 5.05714 & 3.24286 & 4.02267 & 3.38375 & 2.869333 & 0.70667 & 0 & 0 & 0 & 0 & 0 & 0 & 0 & 0 & 0 & 0 & 0 & 0 & 0.30267 & 0.36 & 2.74 & 0.64875 \\
\hline \multicolumn{3}{|c|}{ (mmhari) } & 15 & 15 & 14 & 14 & 15 & 16 & 15 & 15 & 15 & 15 & 15 & 15 & 15 & 16 & 15 & 16 & 15 & 15 & 15 & 16 & 15 & 15 & 15 & 16 \\
\hline
\end{tabular}

Sumber : Hasil perhitungan 2019

\subsection{Perhitungan Curah Hujan Efektif (Re)}

Hujan efektif harian adalah $70 \%$ dari $80 \%$ probabilitas untuk tanaman padi. Untuk palawija metode yang digunakan didasarkan pada curah hujan tengah bulanan, dengan kemungkinan tidak terpenuhi $50 \%$. Hasil perhitungan curah hujan efektif $(\mathrm{Re})$ dapat dilihat pada tabel di bawah ini : 
Tabel 6 Perhitungan Curah Hujan Efektif $(R e)$

\begin{tabular}{|c|c|c|c|c|c|}
\hline \multirow[t]{2}{*}{ BULAN } & \multirow[t]{2}{*}{ R 80} & $R e=0,7 \times R 80$ & Re Padi & $R e=0,5 \times R 80$ & Re Palawija \\
\hline & & $(\mathrm{mm})$ & (mm/hari) & $(\mathrm{mm})$ & (mm/hari) \\
\hline $\mathbf{a}$ & b = Data & $c=\left(0,7^{*}\right) b$ & $d=(c / 15)$ & $\left.e=0,5^{\star} b\right)$ & $f=(e / 15)$ \\
\hline \multirow[t]{2}{*}{ JANUARI } & 8,02 & 5,61 & 0,37 & 4,01 & 0,27 \\
\hline & 41,7 & 29,2 & 1,95 & 20,9 & 1,39 \\
\hline \multirow[t]{2}{*}{ FEBRUARI } & 70,8 & 49,6 & 3,30 & 35,4 & 2,36 \\
\hline & 45,4 & 31,8 & 2,12 & 22,7 & 1,51 \\
\hline \multirow[t]{2}{*}{ MARET } & 60,3 & 42,2 & 2,82 & 30,2 & 2,01 \\
\hline & 54,1 & 37,9 & 2,53 & 27,1 & 1,80 \\
\hline \multirow[t]{2}{*}{ APRIL } & 43,0 & 30,1 & 2,01 & 21,5 & 1,43 \\
\hline & 10,6 & 7,42 & 0,49 & 5,30 & 0,35 \\
\hline \multirow[t]{2}{*}{ MEY } & 0 & 0 & 0 & 0 & 0 \\
\hline & 0 & 0 & 0 & 0 & 0 \\
\hline \multirow[t]{2}{*}{ JUNI } & 0 & 0 & 0 & 0 & 0 \\
\hline & 0 & 0 & 0 & 0 & 0 \\
\hline \multirow[t]{2}{*}{ JULI } & 0 & 0 & 0 & 0 & 0 \\
\hline & 0 & 0 & 0 & 0 & 0 \\
\hline \multirow[t]{2}{*}{ AGUSTUS } & 0 & 0 & 0 & 0 & 0 \\
\hline & 0 & 0 & 0 & 0 & 0 \\
\hline \multirow[t]{2}{*}{ SEPTEMBER } & 0 & 0 & 0 & 0 & 0 \\
\hline & 0 & 0 & 0 & 0 & 0 \\
\hline \multirow[t]{2}{*}{ OKTOBER } & 0 & 0 & 0 & 0 & 0 \\
\hline & 0 & 0 & 0 & 0 & 0 \\
\hline \multirow[t]{2}{*}{ NOVEMBER } & 4,54 & 3,18 & 0,21 & 2,27 & 0,15 \\
\hline & 5,40 & 3,78 & 0,25 & 2,70 & 0,18 \\
\hline \multirow[t]{2}{*}{ DESEMBER } & 41,1 & 28,8 & 1,92 & 20,6 & 1,37 \\
\hline & 10,4 & 7,27 & 0,48 & 5,19 & 0,35 \\
\hline
\end{tabular}

Sumber : Hasil perhitungan, 2019

\subsection{Perhitungan Kebutuhan Air Irigasi}

Kebutuhan air irigasi di sawah diambil nilai NFR maksimum dari 6 alternatif pola tata tanam yakni pada alternatif II dengan nilai NFR sebesar 1,34 Itr/dtk/ha. Rincian perhitungan kebutuhan air untuk alternatif II dapat dilihat pada tabel berikut ini : 


\section{Mulai Kegiatan : November I $\quad$ Tabel 7 Perhitungan Kebutuhan Air Tanaman Dan Air Irigas \\ Pola Tanam $\quad \vdots \quad$ Padi-Padi-Palawija}

\begin{tabular}{|c|c|c|c|c|c|c|c|c|c|c|c|c|c|c|c|c|c|c|c|c|c|c|c|c|c|c|}
\hline & & & & & & & & & & & & & & & & & 1. Waktu pe & enyiapan 1 & han padi: & 5 hari $(\mathrm{Av}$ & al tanam: & Nov.1/ $\mathrm{Mr}$ & 2. J Jul 1) & & & \\
\hline No & Keteranga & Satuan & Nops & & & mber & & aari & & oruari & & & $\mathrm{A}_{\mathrm{I}}$ & & $\mathrm{N}$ & & Jur & & $\mathrm{J}$ & & & istus & Septe & ember & & tober \\
\hline No. & Keterangan & & 1 & 2 & 1 & 2 & 1 & 2 & 1 & 2 & 1 & 2 & 1 & 2 & 1 & 2 & \begin{tabular}{l|l|l|}
1 & \\
\end{tabular} & 2 & 1 & 2 & 1 & 2 & 1 & 2 & 1 & 2 \\
\hline 1 & Pola Tanam & & & LP & & & & & PADI I & & & & LP & & & & & PA & & & & & PALAW & & & \\
\hline & & & & & & & & & & & & & & & & & & & & & & & & & & \\
\hline 2 & Koefisien Tanam & & & & & & & & & & & & & & & & & & & & & & & & & \\
\hline & $\mathrm{C} 1$ & & LP & 1.10 & 1.10 & 1.05 & 1.05 & 0.95 & 0.00 & 0.00 & 0.00 & LP & 1.10 & 1.10 & 1.05 & 1.05 & 0.95 & 0.00 & 0.50 & 0.59 & 0.96 & 1.05 & 1.02 & 0.95 & 0.00 & 0.00 \\
\hline & $\mathrm{C} 2$ & & LP & LP & 1.10 & 1.10 & 1.05 & 1.05 & 0.95 & 0.00 & 0.00 & LP & LP & 1.10 & 1.10 & 1.05 & 1.05 & 0.95 & 0.00 & 0.50 & 0.59 & 0.96 & 1.05 & 1.02 & 0.95 & 0.00 \\
\hline & C3 & & LP & LP & LP & 1.10 & 1.10 & 1.05 & 1.05 & 0.95 & 0.00 & LP & LP & LP & 1.10 & 1.10 & 1.05 & 1.05 & 0.95 & 0.00 & 0.50 & 0.59 & 0.96 & 1.05 & 1.02 & 0.95 \\
\hline & C (rata-rata)/k & & LP & LP & LP & 1.08 & 1.07 & 1.02 & 0.67 & 0.32 & 0.00 & LP & LP & LP & 1.08 & 1.07 & 1.02 & 0.67 & 0.48 & 0.36 & 0.68 & 0.87 & 1.01 & 1.01 & 0.66 & 0.32 \\
\hline 3 & Evapotranspirasi (Eto) & $\mathrm{mm} / \mathrm{hr}$ & 3.115 & 3.115 & 2.850 & 2.850 & 2.813 & 2.813 & 2.415 & 2.415 & 2.584 & 2.584 & 3.442 & 3.442 & 2.499 & 2.499 & 2.446 & 2.446 & 2.608 & 2.608 & 2.754 & 2.754 & 2.966 & 2.966 & 3.162 & 3.162 \\
\hline 4 & Perkolasi $(\mathrm{P})$ & $\mathrm{mm} / \mathrm{hr}$ & 2.00 & 2.00 & 2.00 & 2.00 & 2.00 & 2.00 & 2.00 & 2.00 & 2.00 & 2.00 & 2.00 & 2.00 & 2.00 & 2.00 & 2.00 & 2.00 & 2.00 & 2.00 & 2.00 & 2.00 & 2.00 & 2.00 & 2.00 & 2.00 \\
\hline 5 & Penggunaan Konsumtif & $\mathrm{mm} / \mathrm{hr}$ & 9.74 & 9.74 & 9.56 & 3.08 & 3.01 & 2.87 & 1.62 & 0.77 & 0.00 & 9.38 & 9.97 & 9.97 & 2.70 & 2.67 & 2.50 & 1.64 & 1.25 & 0.94 & 1.87 & 2.40 & 3.00 & 3.00 & 2.09 & 1.01 \\
\hline & $(\mathrm{Etc})=\mathrm{kx}(\mathrm{ETo})$ & & & & & & & & & & & & & & & & & & & & & & & & & \\
\hline 6 & Penggantian Lapisan Air & $\mathrm{mm} / \mathrm{hr}$ & & & & & & & & & & & & & & & & & & & & & & & & \\
\hline & WLR1 & & & & & 3.30 & & 3.30 & & & & & & & 3.30 & & 3.30 & & & & & & & & & \\
\hline & WLR2 & & & & & & 3.30 & & 3.30 & & & & & & & 3.30 & & 3.30 & & & & & & & & \\
\hline & WLR3 & & & & & & & 3.30 & & 3.30 & & & & & & & 3.30 & & 3.30 & & & & & & & \\
\hline & WLR (rata-rata) & & & & & 1.10 & 1.10 & 2.20 & 1.10 & 1.10 & & & & & 1.10 & 1.10 & 2.20 & 1.10 & 1.10 & & & & & & & \\
\hline 7 & Total Kebuthan Air bersih & $\mathrm{mm} / \mathrm{hr}$ & 11.74 & 11.74 & 11.56 & 6.18 & 6.11 & 7.07 & 4.72 & 3.87 & 2.00 & 11.38 & 11.97 & 11.97 & 5.80 & 5.77 & 6.70 & 4.74 & 4.35 & 2.94 & 3.87 & 4.40 & 5.00 & 5.00 & 4.09 & 3.01 \\
\hline 8 & Hujan Efektif $(R e)$ & $\mathrm{mm} / \mathrm{hr}$ & 0.21 & 0.25 & 1.92 & 0.48 & 0.37 & 1.95 & 3.30 & 2.12 & 2.82 & 2.53 & 2.01 & 0.49 & 0.00 & 0.00 & 0.00 & 0.00 & 0.00 & 0.00 & 0.00 & 0.00 & 0.00 & 0.00 & 0.00 & 0.00 \\
\hline 9 & Kebutuhan Air bersih & $\mathrm{mm} / \mathrm{hr}$ & 11.53 & 11.49 & 9.64 & 5.69 & 5.74 & 5.12 & 1.41 & 1.75 & 0.00 & 8.85 & 9.96 & 11.48 & 5.80 & 5.77 & 6.70 & 4.74 & 4.35 & 2.94 & 3.87 & 4.40 & 5.00 & 5.00 & 4.09 & 3.01 \\
\hline 10 & Kebutuhan Air Irigasi di sawah $(N F R)$ & Itr/dtk/ha & 1.34 & 1.33 & 1.12 & 0.66 & 0.67 & 0.59 & 0.16 & 0.20 & 0.00 & 1.03 & 1.16 & 1.33 & 0.67 & 0.67 & 0.78 & 0.55 & 0.50 & 0.34 & 0.45 & 0.51 & 0.58 & 0.58 & 0.47 & 0.35 \\
\hline 11 & Efisiensi Irigasi $(e)$ & & 0.65 & 0.65 & 0.65 & 0.65 & 0.65 & 0.65 & 0.65 & 0.65 & 0.65 & 0.65 & 0.65 & 0.65 & 0.65 & 0.65 & 0.65 & 0.65 & 0.65 & 0.65 & 0.65 & 0.65 & 0.65 & 0.65 & 0.65 & 0.65 \\
\hline 12 & Kebutuhan Air Irigasi di Intake (DR) & Itt/dtkha & 2.06 & 2.06 & 1.73 & 1.02 & 1.03 & 0.92 & 0.25 & 0.31 & 0.00 & 1.58 & 1.78 & 2.05 & 1.04 & 1.03 & 1.20 & 0.85 & 0.78 & 0.53 & 0.69 & 0.79 & 0.89 & 0.89 & 0.73 & 0.54 \\
\hline & Palawija & $\begin{array}{l}\text { Jagung } \\
\text { Kebutuhan }\end{array}$ & di sawa & & & & & & & & & & & & & & & & & & & & & & & \\
\hline & 1 & Pola tata ta & & & & & & & 5 & Hasil perh & tungan & & & & & 9 & (7) - (8) & & & & & & & & & \\
\hline & 2 & Koefisien T & anaman ses & aia tata tar & & & & & 6 & Dari tabel & penggantic & 1 lapisan ait & & & & 10 & (9) $\mathrm{x} 0.116$ & & & & & & & & & \\
\hline & 3 & Hasil perhit & ingan Evap & transpiras & & & & & 7 & (4) $+(5)$ & & & & & & 11 & Effisiensi Iri & & & & & & & & & \\
\hline & 4 & Perkolasid & ketahui ses & ai jenis tar & aman & & & & 8 & Hasil perh & tungan hu & n efektif & & & & 12 & $(10) /(11)$ & & & & & & & & & \\
\hline & & & & & & & Kebutuha & a air mak: & & & & & Padi & & (musm ta & & & $\mathrm{NFR}=$ & 2.06 & & & & & & & \\
\hline & & & & & & & & & & & & & Padi & & (musim ta & & & $\mathrm{NFR}=$ & 1.78 & & & & & & & \\
\hline & & & & & & & & & & & & & Palawija & & (musim tas & & & $\mathrm{NFR}=$ & 0.79 & & & & & & & \\
\hline
\end{tabular}

Sumber Hasil perhitungan, 2019 


\subsection{Perhitungan Debit Rencana Saluran}

Kebutuhan air maksimum ditetapkan 1,34 Itr/dtk/ha, untuk menghitung kapasitas rencana pembagian air bila $Q_{\text {maks }}=100 \%$

1. Saluran Sekunder (SSR.1)

Data:

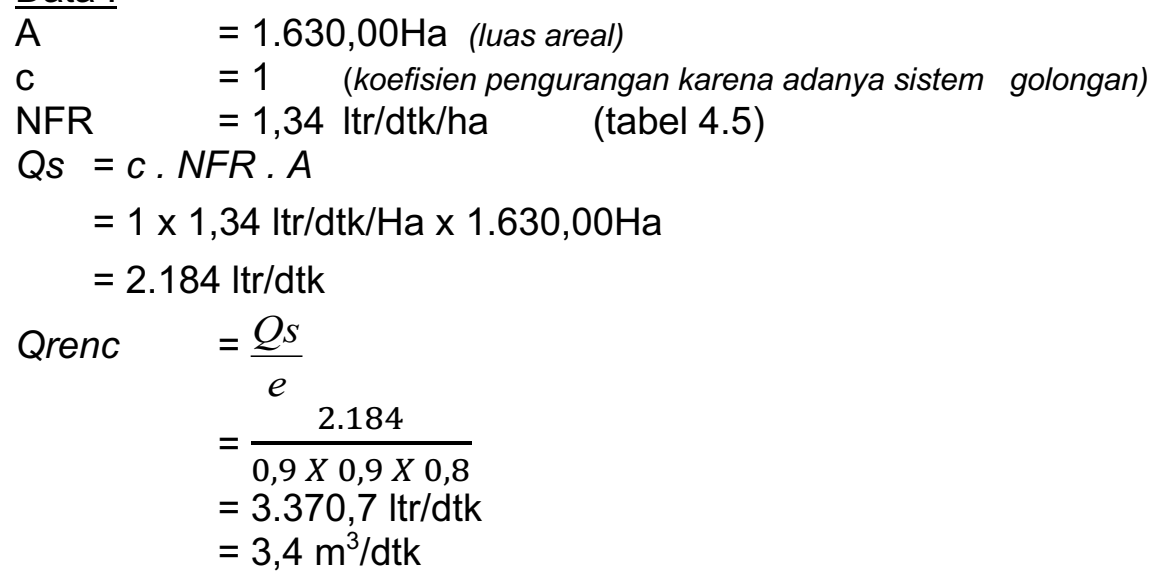

\section{Saluran Sekunder (SSR.2)}

Data:

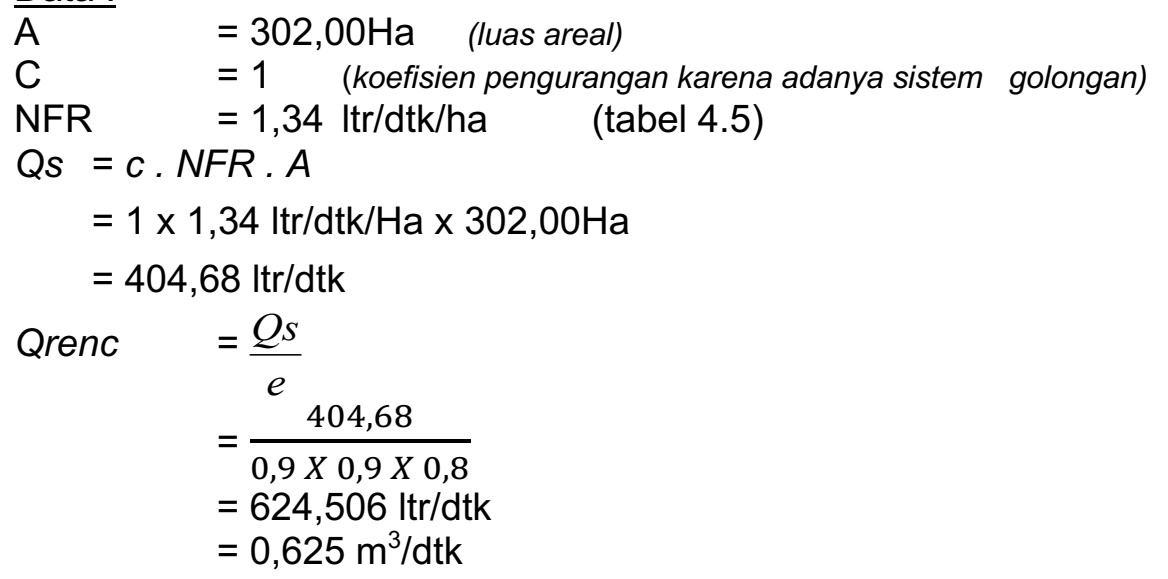

\subsection{Perhitungan Dimensi Saluran}

Dari hasil analisa perhitungan dimensi saluran sekunder, maka diperoleh hasil sebagai berikut:

1. Saluran Sekunder (SSR.1) ruas B.BG.1-B.G.2 = 1.630,00 Ha.

$\begin{array}{ll}\text { Debit saluran (Q) } & =3,4 \mathrm{~m}^{3} / \mathrm{dtk} \\ \text { Luas penmpang (A) } & =5,60 \mathrm{~m}^{2} \\ \text { Kecepatan aliran (V) } & =0,60 \mathrm{~m} / \mathrm{dtk} \\ \text { Tingga jagaan }(\mathrm{W}) & =0,25 \mathrm{~m} \\ \text { Kemiringan dasar saluran }(\mathrm{I}) & =0,0018559\end{array}$

2. Saluran Sekunder (SSR.2) ruas B.BG.1-B.B.LM.1 $=302,00 \mathrm{Ha}$.

\begin{tabular}{|c|c|}
\hline Debit saluran (Q) & $=0.625 \mathrm{~m}^{3} / \mathrm{dtk}$ \\
\hline Luas penmpang (A) & $=1,24 \mathrm{~m}^{2}$ \\
\hline Kecepatan aliran (V) & $=0,50 \mathrm{~m} / \mathrm{dtk}$ \\
\hline Lebar saluran (b) & $=1,65 \mathrm{~m}$ \\
\hline Tinggi muka air (h) & $=0,75 \mathrm{~m}$ \\
\hline Tingga jagaan $(\mathrm{w})$ & $=0,25 \mathrm{~m}$ \\
\hline Kemiringan dasar saluran (I) & $=0,0267291$ \\
\hline
\end{tabular}

46 Kajian Kapsitas Saluran Daerah Irigasi Baing di Kabupaten Sumba Timur Provinsi Nusa Tenggara Timur (Muchamad Aruf Budiyanto, Tornado M. Ratu Ropa) 


\section{PENUTUP}

\subsection{Kesimpulan}

Berdasarkan pembahasan yang telah diuraikan pada BAB IV dengan perhitungan yang panjang, maka dapat diambil kesimpulan sebagai berikut:

1. Perhitungan kebutuhan air irigasi menggunakan pola tata tanam "Padi-PadiPalawija" dengan mulai tanam pada bulan November I sampai dengan Bulan Januari II. Perhitungan dilakukan dengan enam alternatif tanam yakni periode tanam November I, November II, Desember I, Desember II, Januari I, Januari II. Berdasarkan hasil perhitungan kebutuhan air maksimum tanaman dari alternatif periode tanam November I sampai dengan periode tanam Januari II maka didapatkan kebutuhan air di sawah (NFR) sebesar 1,34 ltr/dtk/ha.

2. Berdasarkan hasil perhitungan debit saluran, maka diperoleh dimensi saluran sekunder seperti terlihat pada gambar di bawah ini:

a. Saluran Sekunder (SSR.1) ruas B.BG.1-B.G.2 = 1.630,00 Ha.

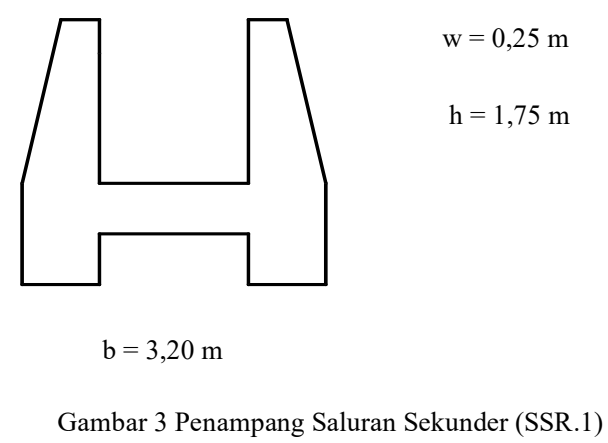

b. Saluran Sekunder (SSR.2) ruas B.BG.1-B.B.LM.1 = 302,00 Ha.

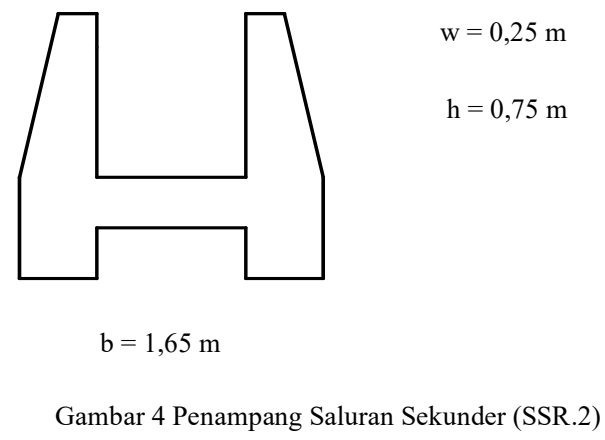




\subsection{Saran}

Mengingat air merupakan kebutuhan yang sangat vital bagi suatu daerah irigasi maka diharapkan agar :

1. Untuk memperoleh hasil perhitungan yang optimal dalam analisa hidrologi suatu proyek irigasi, maka penulis menyarankan agar adanya data yang lengkap dan akurat sebagai penunjang perencanaan yang matang dan ketelitian dalam menganalisa data.

2. Untuk menjaga agar fungsi dari saluran tetap berfungsi dengan baik, maka perlu adanya pemeliharaan yang rutin.

3. Untuk pemilihan pola tata tanam yang baik maka perlu diperhatikan faktorfaktor yang mempengaruhi pola tata tanam pada daerah tersebut karena karakteristik setiap daerah berbeda-beda.

\section{DAFTAR PUSTAKA}

[BNPB] Badan Nasional Penanggulangan Bencana. 2018. Laporan Kinerja Tahunan. Jakarta: BNPB.

[BWS] Balai Wilayah Sungai NTT. 2014. Buku Data dan Inventarisasi Daerah Irigasi. Kupang (ID): Balai Wilayah Sungai NTT II Nusa Tenggara Timur.

Akmal, dkk. 2014. Efisiensi Irigasi Pada Petak Tersier Di Daerah Irigasi Lawe Bulan Kabupaten Aceh Tenggara. Banda Aceh : Universitas Syiah Kuala. https://www.semanticscholar.org/paper/efisiensi-irigasi-pada-petak-tersier-didaerah-lawe-akmal/26.

Arif Budiyanto, M., 2010. Kajian Pengaruh Pengembangan Pemanfaatan Air Irigasi dan Air Domestik Terhadap Alokasi Air di DAS Opak. Yogyakarka: UGM.

Bolanos, M. G. et al. 2011. Performance assessment of small irrigation schemes along the Mauritanian banks of the Senegal River. Diambildari: https://www.researchgate.net/publication/227411410 Performance ass essment of small irrigation schemes along the Mauritanian banks of the Sene gal River.

C. D Soemarto, B.I.E. Dipl. H. 1999. Hidrologi Teknik, Penerbit Erlangga, Jakarta.

Dinas PU Kabupaten Sumba Timur. 2014. Buku Data dan Inventarisasi Embung. Waingapu (ID): Dinas PU Kabupaten Sumba Timur, Nusa Tenggara Timur.

Direktorat Jenderal Pengairan, Departemen Pekerjaan Umum. 2013. Standar Perencanaan Irigasi Kriteria Perencanaan Jaringan Irigasi, KP-01.

Direktorat Jenderal Pengairan, Departemen Pekerjaan Umum. 2013. Standar Perencanaan Irigasi Kriteria Perencanaan Saluran, KP-03.

Direktorat Jenderal Pengairan, Departemen Pekerjaan Umum. 2013. Standar Perencanaan Irigasi Kriteria Perencanaan Bangunan, KP-04.

Februarman. 2009. Jenis dan Ragam Kerusakan Saluran Primer Daerah Irigasi Bandar Laweh Kabupaten Solok. Jurnal Rekayasa Sipil, 5(1): 57-66

H. Erman Mawardi, Dipl. AIT. 2002. Pengertian Irigasi, Alfabeta, Bandung.

48 Kajian Kapsitas Saluran Daerah Irigasi Baing di Kabupaten Sumba Timur Provinsi Nusa Tenggara Timur (Muchamad Aruf Budiyanto, Tornado M. Ratu Ropa) 
Hansen, dkk. 1990. Arti Irigasi Secara Umum, Penerbit Erlangga, Jakarta.

Hariany, Susi, dkk. 2011. Evaluasi Kinerja Jaringan Irigasi Di Saluran Sekunder Pada Berbagai Tingkat Pemberian Air Di Pintu Ukur. Jurnal Rekayasa, Vol.15. https://jurnalpengairan.ub.ac.id/index.php/jtp/article/view/16 